Distortion and crack formation in green and seasoned timber - Influence of annual ring orientation in the cross section

Dick Sandberg, PhD

Växjö University, School of Industrial Engineering

Submitted paper no. 2004:11

Växjö University,

School of Industrial Engineering

SE-351 95 VÄXJÖ

Dick.Sandberg@ips.vxu.se

Telephone +46 470708296

Fax + 46470768540 


\title{
Distortion and crack formation in green and seasoned timber - Influence of annual ring orientation in the cross section
}

\author{
Dick Sandberg, PhD \\ Växjö University, School of Industrial Engineering
}

\begin{abstract}
This work describes distortion (bow, crook, twist, cup) and crack formation in green and seasoned timber of Scots pine and Norway spruce. Distortion and crack formation have been evaluated according to their original location in the cross section of the log. The purpose is to describe differences in distortion and crack formation between sawn timber taken from star-sawing and from traditional sawing patterns.
\end{abstract}

Bow and crook occur in the green timber immediately after sawing as a result of growth stress release. During seasoning bow and crook change in both magnitude and direction. The green timber pieces are normally distorted (concave) to the sapwood side as a result of growth stresses. The direction is most apparent in pieces that are sawn close to the pith. However, during seasoning, due to the high longitudinal shrinkage of the juvenile wood, this timber will become straighter or the distortion may even change direction to the direction opposite to that before seasoning.

Twist and cup do not occur directly after sawing but arise during seasoning of the timber. In sawn timber, the pith and juvenile wood have a major influence on the twist. This means that timber sawn close to the pith shows a greater twist than timber sawn away from the pith. Cupping increases with decreasing radius of curvature of the annual rings in the cross section of the timber.

Cracks occur in timber before seasoning. The pattern of crack formation is the same in both pine and spruce, timber sawn close to the pith or with pith enclosed has a considerable higher relative crack length than timber sawn away from the pith. Cracks occur mainly on surfaces orientated to the pith, a fact that gets more clear when timber is observed close to the pith.

Seasoned star-sawn timber with a rectangular cross section has bow and crook of the same level as or less than that of timber sawn according to traditional sawing patterns. Seasoned star-sawn timber with a triangular cross section has high bow, as a result of the stacking method. The crook is comparably low. star-sawn timber does not show any cup. It also has a very small twist and shows very few cracks after seasoning. 


\section{Introduction}

Cracks and major distortion can make timber unusable for some applications. Various kinds of deformations in sawn timber, usually referred to as warp, can be a consequence of primary stresses in the log, so-called growth stresses, and they may also arise during processing, especially when timber is being dried.

The anisotropic, hygroscopic and non-homogeneous nature of wood creates feasible conditions for distortion. Shape stability refers to the ability of the timber to maintain a given geometrical shape during use. This concerns on the one hand the distortion of the timber in the longitudinal direction, i.e. crook, bow and twist and, on the other hand, the change in shape of the timber in the cross section, e.g. cupping. Vertical annual rings affect primarily the shape stability in the cross section of the timber (CEN 1995, Sandberg 1995), figure 1.

The influence of juvenile wood on distortion has been investigated by several researchers, including Hallock (1965), Balodis (1972), Danborg (1990) and Perstorper et al. (1995). Zobel et al. (1998) have made a thorough documentation of the properties of juvenile wood with its effects on among other things solid wood products. Their results show that the presence of juvenile wood normally increases distortion in softwood. Sandberg (1996a) has also shown that the presence of juvenile wood increases crack formation in Scots pine and Norway spruce timber.

A new method of sawing, star-sawing, to produce pith-free timber with vertical annual rings and without juvenile wood has been proposed (Sandberg 1996b). It has been shown that timber produced by this method is less subject to cracking, especially when the timber is exposed to moisture variations, than timber produced accoding to traditional sawing methods (Sandberg 1997a, 1997b).

The object of this work was to study the influence of the original location of the timber with respect to the cross section of the log, i.e. annual ring orientation, growth stresses, juvenile wood and location of the pith, on distortion and crack formation in timber sawn from over-sized logs of Scots pine (Pinus sylvestris $L$ ) and Norway spruce (Picea abies Karst). The purpose is to describe differences in distortion and crack formation between timber sawn according to the star-sawing pattern and traditional sawing patterns.

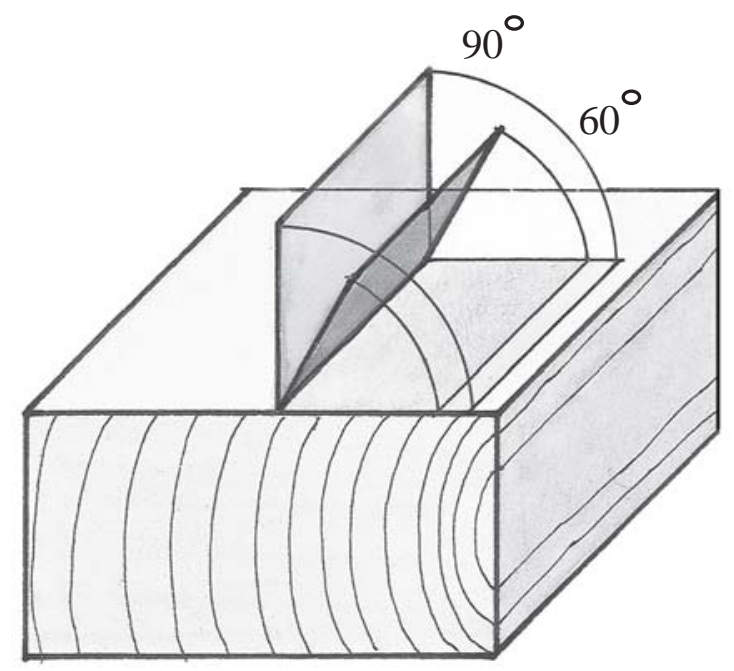

Figure 1. The annual ring orientation is determined from the cross-section of the timber. When the annual rings are practically perpendicular to the flat face of the timber, the timber is considered to have vertical annual rings. 


\section{Materials and methods}

\section{$2.1 \quad$ Log selection and sawing}

The timber for the investigation was of forest scale quality and was taken from three areas in southern, central and northern Sweden. The dimensions of the timber chosen were in the first place adapted for the star-sawing pattern, figure 2a. Table 1 shows the extent and average dimensions of the original material.

In this investigation, juvenile wood was defined as the 15 annual rings closest to the pith. At both ends of each log, the juvenile wood was colour-marked so that it would be possible to identify and determine the juvenile wood content in the sawn wood. The proportion of juvenile wood in the sawn wood was defined as the mean value of the area proportion of juvenile wood at the root end and top end of the wood in relation to the cross-section area of the wood piece.

Table 1. Numbers and dimensions of the timber used in the investigation. The grade was forest scale.

\begin{tabular}{|c|c|c|c|c|c|}
\hline \multirow[t]{2}{*}{ Spieces } & \multirow{2}{*}{$\begin{array}{l}\text { number } \\
\text { of logs }\end{array}$} & \multicolumn{2}{|c|}{ Length (m) } & \multicolumn{2}{|c|}{ Top diameter $(\mathrm{cm})$} \\
\hline & & mean & std & mean & std \\
\hline Pine & 44 & 4.5 & 0.5 & 38 & 3.5 \\
\hline Spruce & 63 & 4.5 & 0.6 & 38 & 6.4 \\
\hline
\end{tabular}

The sawing was carried out according to three sawing patterns: star-sawing, through-and-through sawing and a combination of these, as shown in figure 2. By splitting parts of the through-and-through sawn wood into two or three pieces, a further variation of the annual ring direction in the cross-section was obtained, figure $2 b-c$. All the pieces were edged immediately after the division. The edging was carried out as parallel as possible with the pith direction of the wood, i.e. no so-called taper edging was carried out.

Timber with a rectangular or triangular cross-section was stacked in separate packages. The rectangular wood was stacked in a conventional way while the triangular pieces were put together into groups of three (Sandberg 1998). The whole test material was then dried simultaneously in a drying chamber with the same drying schedule. All the wood packages were placed in the lower half of the drying batch to prevent the wood pieces from drying completely without load. After the drying, the wood was conditioned for three months at $20^{\circ} \mathrm{C}$ and $55 \% \mathrm{RH}$, which meant that the wood reached a moisture ratio of $9.6 \pm 0.7 \%$.
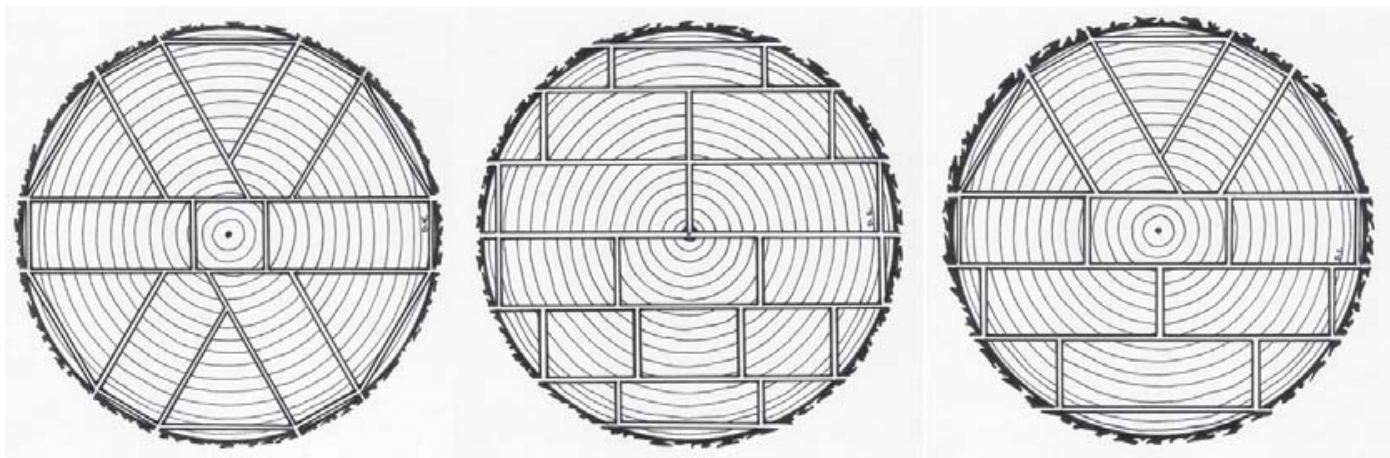

Figure 2. An example of the sawing patterns used in the division of the timber for this investigation: (a) star-sawing, (b) through-and-through sawing, and (c) a combination of star-sawing and through-and-through sawing. 


\section{$2.2 \quad$ Test material}

The different sawing patterns and the variation in log diameter have meant that the sawn-out crosssectional dimensions have varied. The thickness of the dried wood has been 50 or $60 \mathrm{~mm}$. The width has varied between 75 and $150 \mathrm{~mm}$ in standard modules. The wood with a triangular cross-section has been sawn with sides of 70, 80, 90, 100, 110 and $120 \mathrm{~mm}$.

After the division, the wood was divided into groups with respect to the annual ring orientation in the cross-section of the wood, as indicated in figure 3. This division subsequently provided the basis for the evaluation of deformation and crack occurrence. Table 2 shows the final extent of the test material and table 3 shows the average density of the wood in the different groups.

Table 2. The extent of the material tested: numbers of wood pieces in each group with respect to the annual ring orientation in the cross-section of the wood.

\begin{tabular}{lcccccccc|c}
\hline \multicolumn{7}{c}{ Annual ring orientation } \\
& A & B & C & D & E & F & G & H & A-H \\
\hline Pine & 22 & 95 & 6 & 30 & 43 & 8 & 25 & 88 & 317 \\
Spruce & 27 & 116 & 18 & 28 & 79 & 16 & 31 & 117 & 432 \\
\hline S:a & 49 & 211 & 24 & 58 & 122 & 24 & 56 & 205 & 749 \\
\hline
\end{tabular}

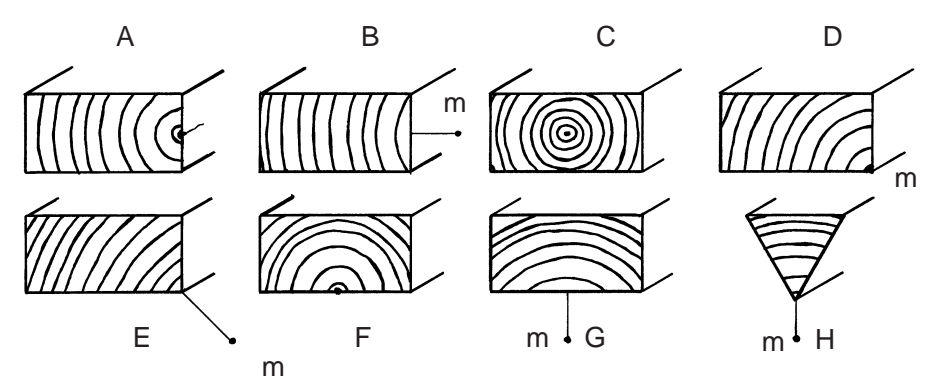

Figure 3. Distribution of the wood into groups (A-H) with different annual ring orientations in the wood crosssection. The location of the pith is marked "m" for the pieces B, D, E, G, H. In the case of the pieces A, C and $\mathrm{F}$, the pith lies along one edge side, in the middle, and along one face of the wood, respectively.

A - Radially sawn, with the pith remaining along one edge side.

B - Star-sawn, vertical annual rings and with a distance from the pith greater than $25 \mathrm{~mm}$.

C - The pith enclosed in the wood piece, so-called "pith-in-the-middle".

$\mathrm{D}$ - The pith running in the region between one edge side and the face. An annual ring orientation of about 45 degrees.

E - An annual ring orientation of about 45 degrees and sawn at a distance from the pith greater than $25 \mathrm{~mm}$.

F - The pith running on one face and strongly "bent” annual rings in the cross-section (horizontal annual rings).

$\mathrm{G}$ - Horizontal annual rings and sawn at a distance from the pith greater than $25 \mathrm{~mm}$.

$\mathrm{H}$ - Star-sawn, vertical annual rings and sawn at a distance from the pith greater than $25 \mathrm{~mm}$. 
Table 3.

Compilation of density data.

\begin{tabular}{llllllllll}
\hline & & A & B & C & D & E & F & G & H \\
\hline Pine & Mean & 466 & 486 & 450 & 494 & 493 & 474 & 502 & 481 \\
& Std & 38 & 60 & 93 & 77 & 52 & 84 & 53 & 57 \\
Spruce & Mean & 387 & 395 & 379 & 374 & 383 & 393 & 396 & 383 \\
& Std & 33 & 38 & 37 & 29 & 30 & 54 & 34 & 32 \\
\hline
\end{tabular}

\subsection{Distortion and visible crack measurement}

Four different form of distortion are recognised, as illustrated in figure 4, viz.: bow, crook, twist and cup

Measurements of the distortion and crack formation have been made immediately after sawing (0-3 hours) and after seasoning followed by three months' conditioning.

The distortions were determined with respect to the total length and width of the wood. The measured values were then normalised to a wood length of 3 metres and a width of $100 \mathrm{~mm}$. In addition, the direction of the deformation in relation to the pith was determined. For the wood with a rectangular cross-section, the cupping was determined on the concave flat side. For wood with a triangular crosssection, the cupping was determined on the tangential side, after it was established that the cupping was non-existent on the other two sides.

The total length of visible cracks on each surface of the wood was determined directly after sawing and after the drying and conditioning periods. The cracks which were measured directly after the sawing were marked so that it was possible to observe any changes in the propagation of the cracks after drying.

\section{$2.4 \quad$ Statistical methods}

A common complication when analysing experimental results on wood is that the values are not normally distributed. Söderström (1990) has shown that the assumption of a normal distribution when analysing length and areas of cracks is not valid. The results of the present investigation have also indicated that distortion is not normally distributed. For this reason, a non parametric test was used where the results for the test groups were evaluated as mean values (Montgomery 1991). In this statistical method, normally distributed test parameters are not necessary. A confidence interval of 0.95 has been used in all tests.

a)
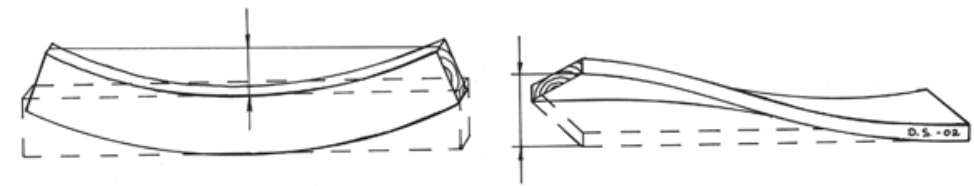

b)
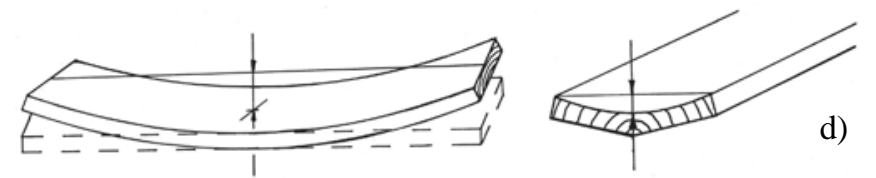

Figure 4. Determination of different types of wood distortion: (a) crook, (b) twist, (c) bow and (d) cup. 


\section{Results}

In the following, the expressions "before drying” and "after drying” will be used. This means the times for deformation and visible crack measurement immediately after the division and after drying and conditioning in accordance with the described procedure (chapter 2.3).

\subsection{Mean values for distortion}

Figure 5a-h shows mean values for distortion, where the timber is grouped according to figure 3.

Figures 5a-b shows the bow before and after the drying for pine and spruce respectively. The statistical analysis shows that in wood sawn according to cases C, D, E and H, spruce exhibits a significantly greater bow than pine both before and after drying. Before the drying, the difference in bow is small between the groups. The only significant deviation is group $\mathrm{B}$ which has the smallest bow before drying. Drying and conditioning in general lead to a marginal increased in bow. The groups which clearly deviate from this pattern are groups $\mathrm{F}$ and $\mathrm{H}$, where the size of the bow is either greatly increased or decreases.

Figure 5c-d shows the crook before and after drying for pine and spruce respectively. It is not possible to show any significant differences between pine and spruce before and after the drying, with the exception of spruce in group $\mathrm{H}$ which exhibits a significantly greater crook than pine. Before drying, the crook is very similar in the different annual ring orientations, except that group $\mathrm{H}$ has a significantly lower crook than the other pieces. Drying and conditioning lead either to a large percentage increase in the crook (group A, E, G and H) or a largely unchanged crook (group B, C, D and F).

Figure $5 e-f$ shows the twist before and after drying for pine and spruce respectively. The only significant differences in twist between pine and spruce are in groups $\mathrm{D}$ and $\mathrm{E}$ after drying. Before drying, the twist is marginal or non-existent, except for group $\mathrm{H}$ which shows a slight twist before drying. Twisting occurs to a considerable extent when the wood is dried, as is clearly shown in figure 5e-f. Group B has the significantly lowest twist after drying.

Figure 5g-h shows cup before and after drying for pine and spruce respectively. It is not possible to find any significant differences between pine and spruce with respect to cup. Before the drying, cupping is non-existent in all the wood pieces. The drying and conditioning cause no cupping of the wood in group $\mathrm{B}$, and only a very slight cupping of the wood in groups A and $\mathrm{H}$. The significantly greatest degree of cupping is found in group $\mathrm{F}$. 


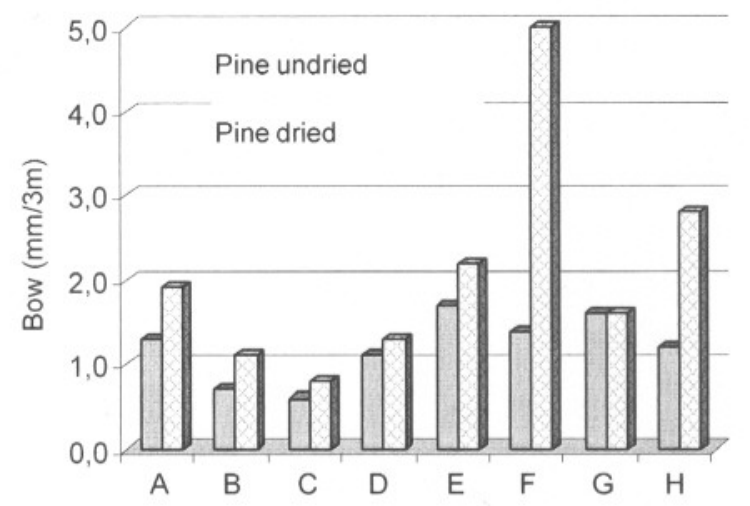

The position of the wood in the log cross-section

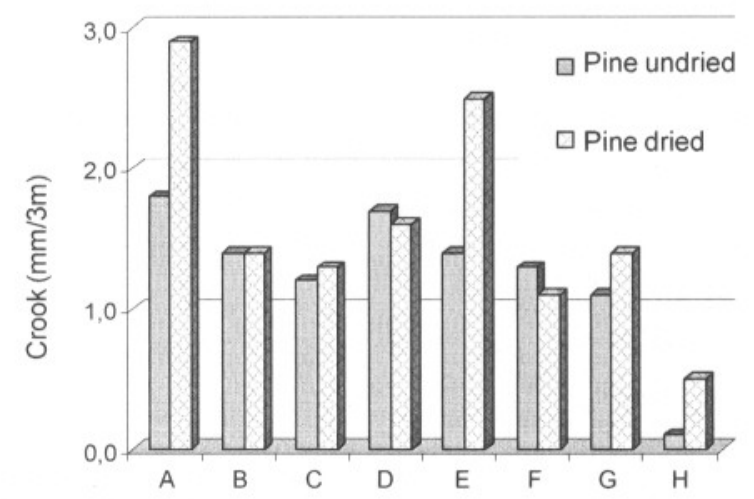

The position of the wood in the log cross-section

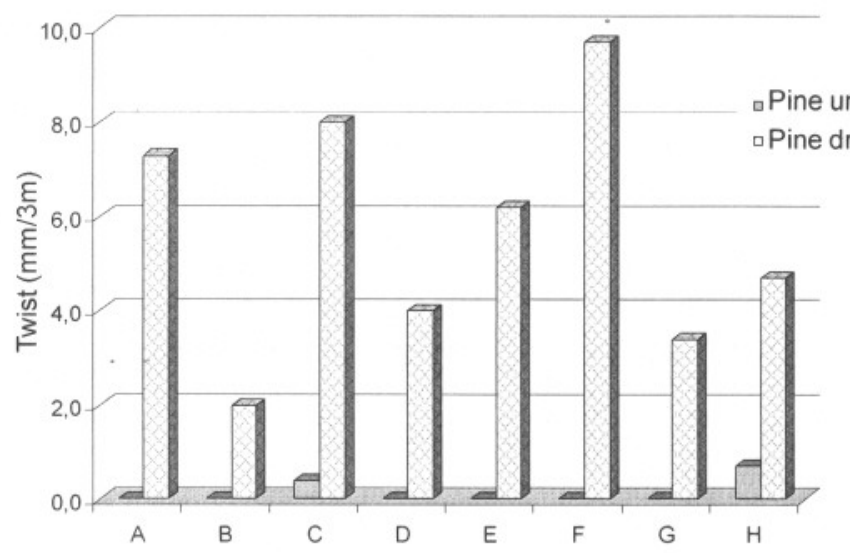

The position of the wood in the log cross-section

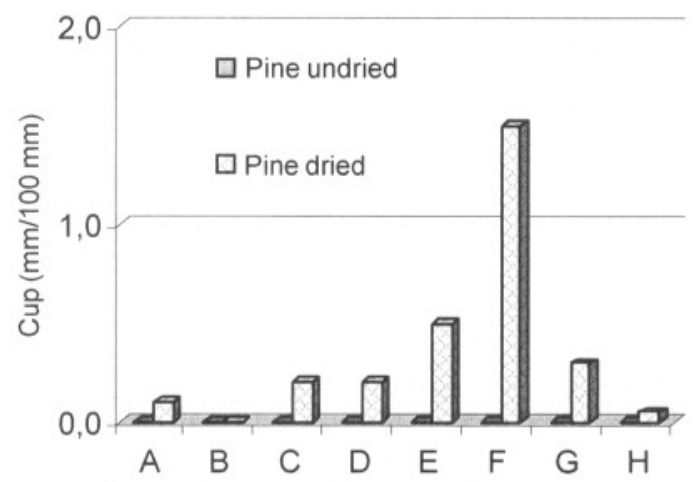

The position of the wood in the log cross-section

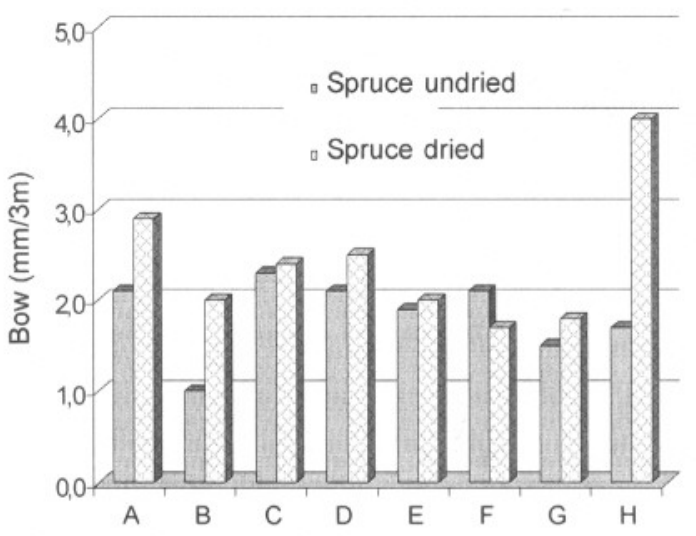

The position of the wood in the log cross-section

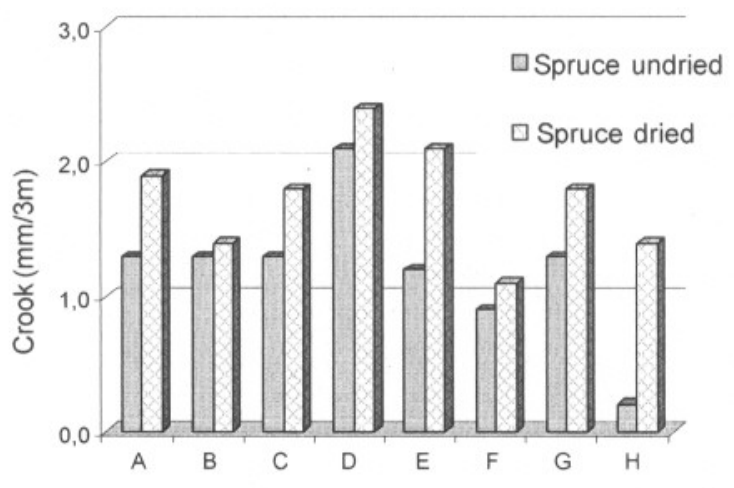

The position of the wood in the log cross-section

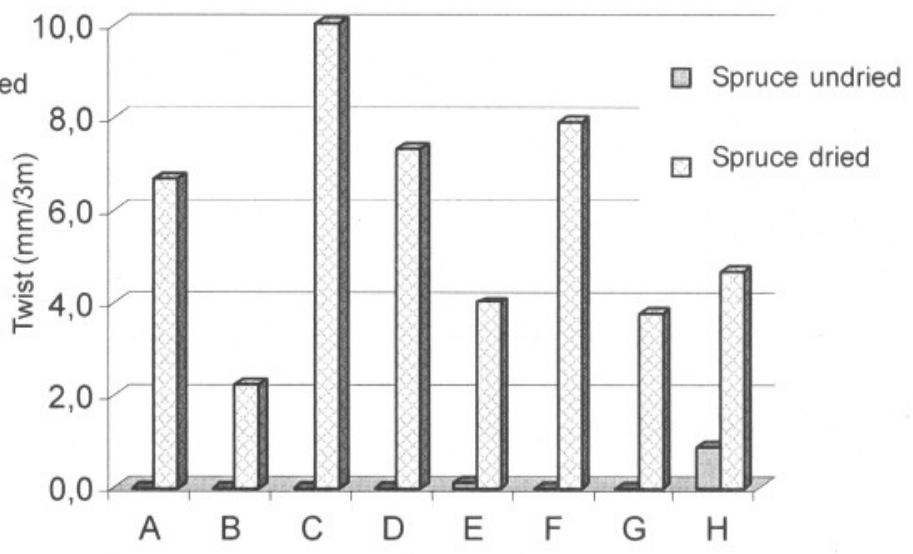

The position of the wood in the log cross-section

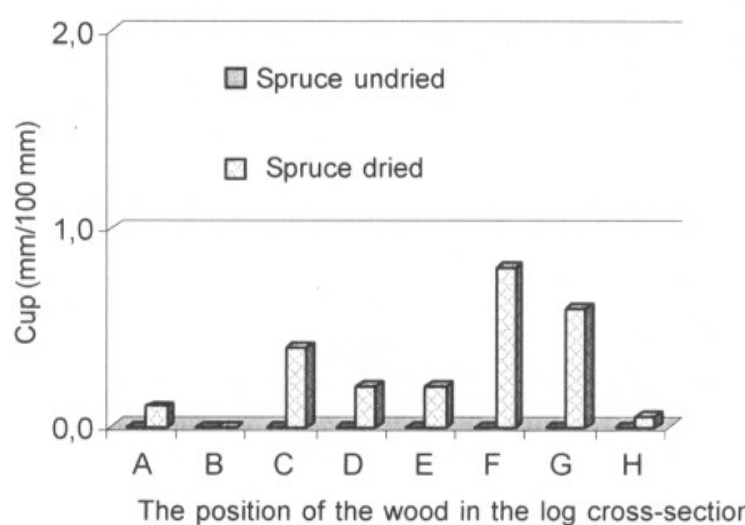

Figure 5. The mean distortion of the wood piece in each annual ring position (A-H), before and after drying for all the samples of pine and spruce. 


\subsection{Changes in direction of bow and crook during seasoning}

Figure 6a-b shows the proportion of all the wood pieces in each group (A-H) before and after drying which exhibit a bowing in a certain direction or no bow.

The proportion of pieces without any bow before the drying is about $10 \%$ and is practically the same in the different groups, figure 6a. Only group B has a significantly higher proportion of pieces without bow $(22 \%)$.

Groups A, B and $\mathrm{C}$ have practically the same proportions of pieces with bowing in either direction. The bow in groups D, E, F, G and $\mathrm{H}$ is clearly directed towards the sapwood side of the wood, i.e. the more or less tangential face, figure $6 \mathrm{a}$.

During drying, the proportion of wood without bow increases in all groups and the direction of the bow changes, as can be seen in figure $6 \mathrm{~b}$. Except for groups $\mathrm{D}$ and $\mathrm{F}$, the direction is more or less random. Groups $\mathrm{D}$ and $\mathrm{F}$ have an overrepresentation of pieces with bowing directed towards the pith, i.e. in the direction opposite to that before drying.
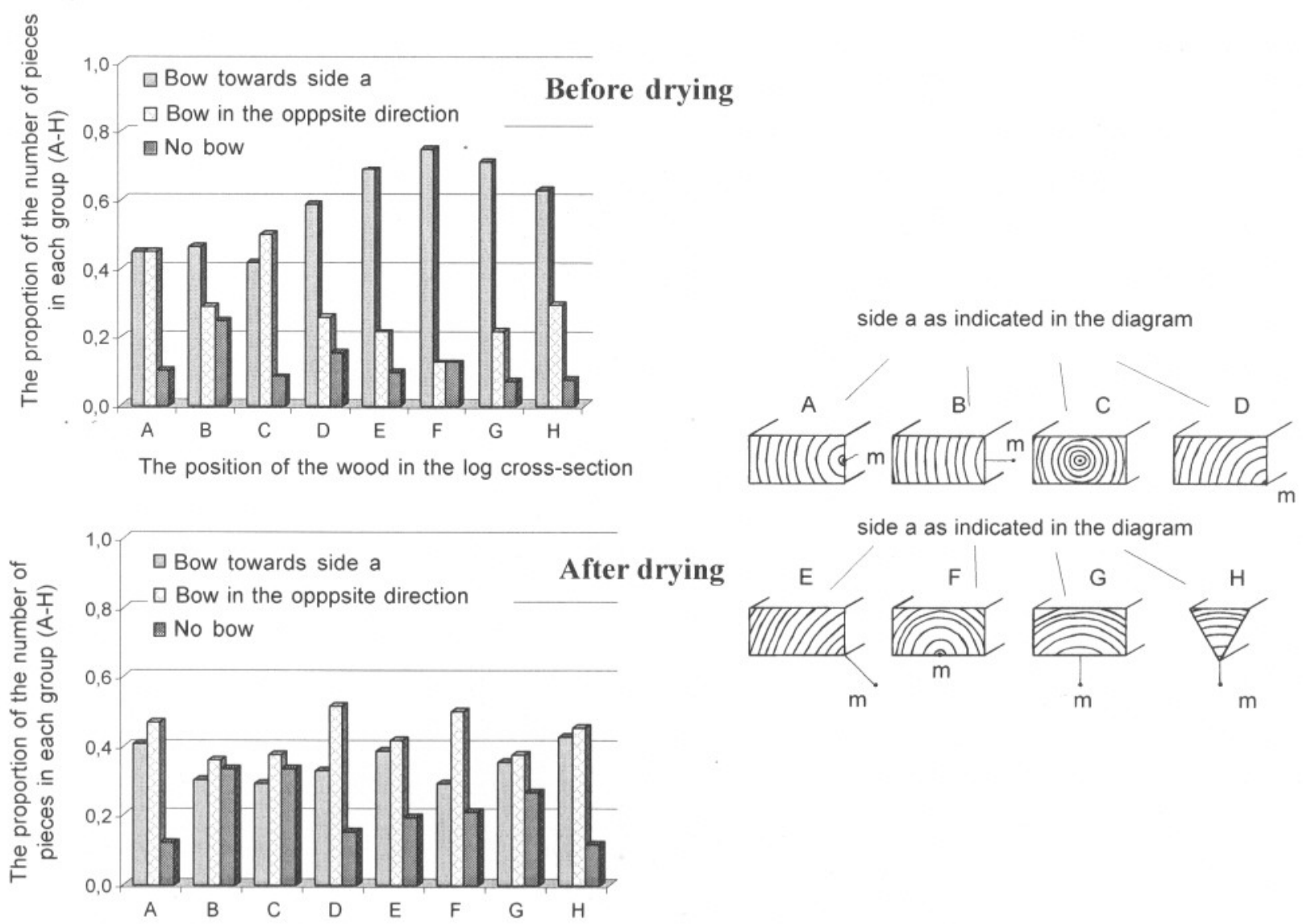

The position of the wood in the log cross-section

Figure 6a-b. The proportion of the number of wood pieces of each annual ring position (A-H) which, before and after drying, have a bow in a given direction, or no bow. Includes all the samples of pine and spruce in each test group. 
Figure 7a-b shows the proportion of all the wood pieces in each group $(\mathrm{A}-\mathrm{H})$ before and after the drying which exhibit crook in a certain direction, or no crook.

Before drying, the proportion of pieces without crook is of the order of $20 \%$, but groups $\mathrm{F}$ and $\mathrm{H}$ have a considerably higher proportion of pieces without crook, figure $7 \mathrm{a}$.

The crook before drying has a clear direction in all the groups. Groups A and D have an overrepresentation of pieces with crook towards the sapwood side of the wood. The corresponding wood pieces sawn further from the pith have in case $\mathrm{B}$ an over-representation of pieces with crook towards the pith and in case E, most of the pieces $(50 \%)$ are concave towards the sapwood side.

During drying, the proportion of wood without crook increases in all the groups except for groups $\mathrm{G}$ and $\mathrm{H}$, figure $7 \mathrm{~b}$. The directional dependence shown by the crook before drying remains the same after the drying for the wood in groups $\mathrm{C}, \mathrm{F}, \mathrm{G}$ and $\mathrm{H}$, but for groups B, D and E, the directional dependence decreases.
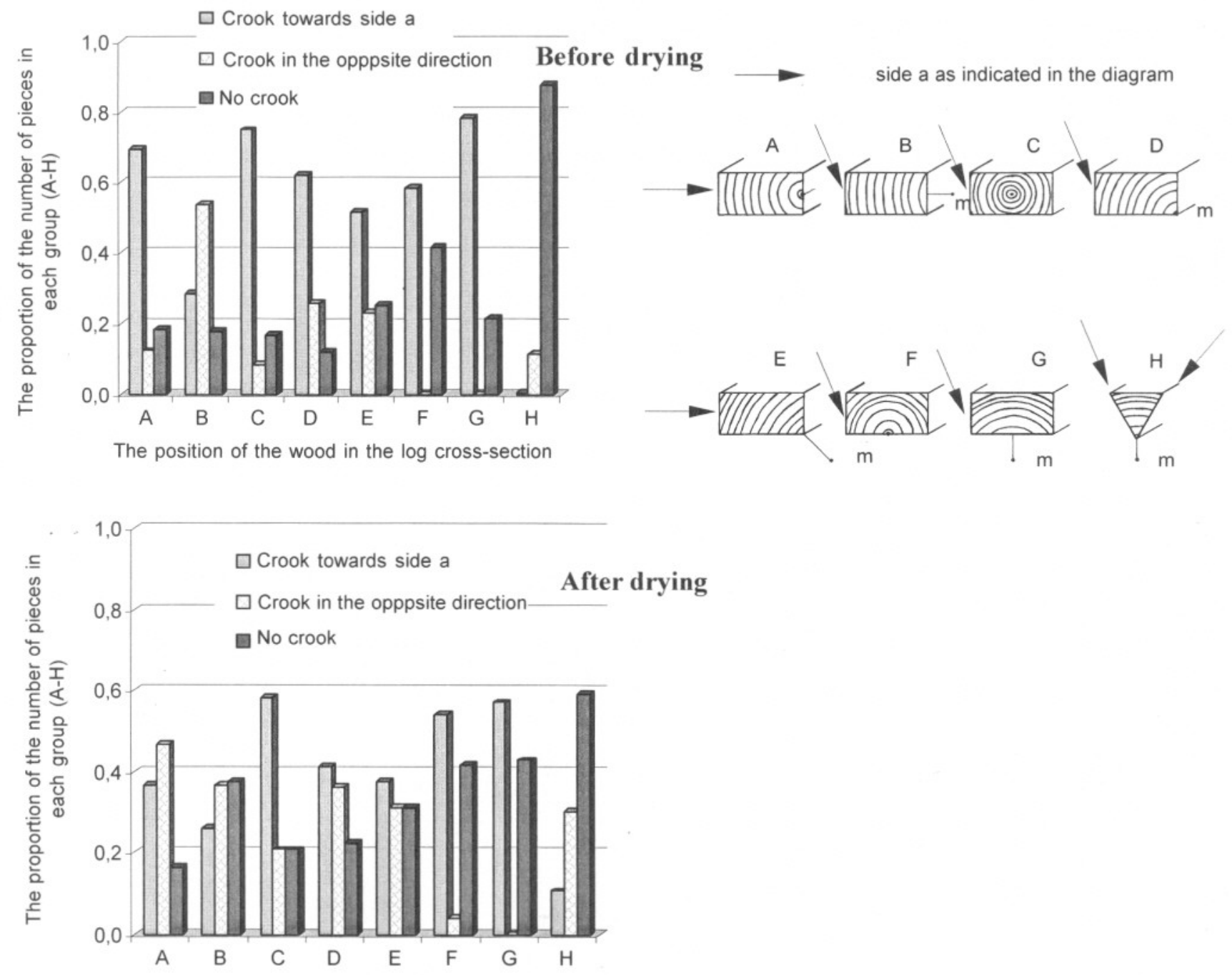

The position of the wood in the log cross-section

Figure 7a-b. The proportion of the number of wood pieces of each annual ring position $(\mathrm{A}-\mathrm{H})$ which, before and after drying, have a crook in a given direction, or no crook. Includes all the samples of pine and spruce in each test group. 


\subsection{Visible crack formation}

Figure 8a-b shows the relative visible crack length in pine and spruce wood before and after drying, where the relative crack length is calculated as the total crack length in the wood in relation to the length of the wood. The wood is grouped according to figure 3 .

Before drying, pine has a significantly shorter average crack length than spruce, except in groups A, F and C. After drying, the crack length is still significantly shorter for pine in groups A-E, but significantly greater in groups $\mathrm{F}$ and $\mathrm{H}$. In the case of group $\mathrm{G}$, there is no significant difference between pine and spruce after drying.

Before drying, the average crack length is greatest in groups A, C, D and F in both pine and spruce. Groups $\mathrm{E}, \mathrm{G}$ and $\mathrm{H}$ in pine are completely without cracks prior to drying.

Drying leads to an increase in crack length for pine in groups A, E, G and H. In the wood in groups B, $\mathrm{C}, \mathrm{D}$ and $\mathrm{F}$, the observed crack length decreases or is unchanged during drying. In the case of spruce, the crack length decreases in all groups except $\mathrm{A}$ and $\mathrm{F}$.

Figure 9 shows the total visible crack length on the pith and non-pith sides of the wood for pine and spruce. Test group C, where the pith is enclosed in the wood, has been omitted because this wood has no unambiguous direction in relation to the pith. The wood in groups $\mathrm{D}, \mathrm{E}$ and $\mathrm{H}$ has two pith sides per wood piece, and the other groups have one pith side. The average visible crack length on the pith sides of the wood in groups A, D and F is considerably greater than the crack length on all the other sides, both pith sides and non-pith sides, in groups A-H. This is true both before and after drying of the wood.

In all groups, the average crack length decreases on the pith sides during the drying, but this is not in general the case on the non-pith sides. Considered group for group, the pith sides in general have a larger average crack length than non-pith sides both before and after drying.
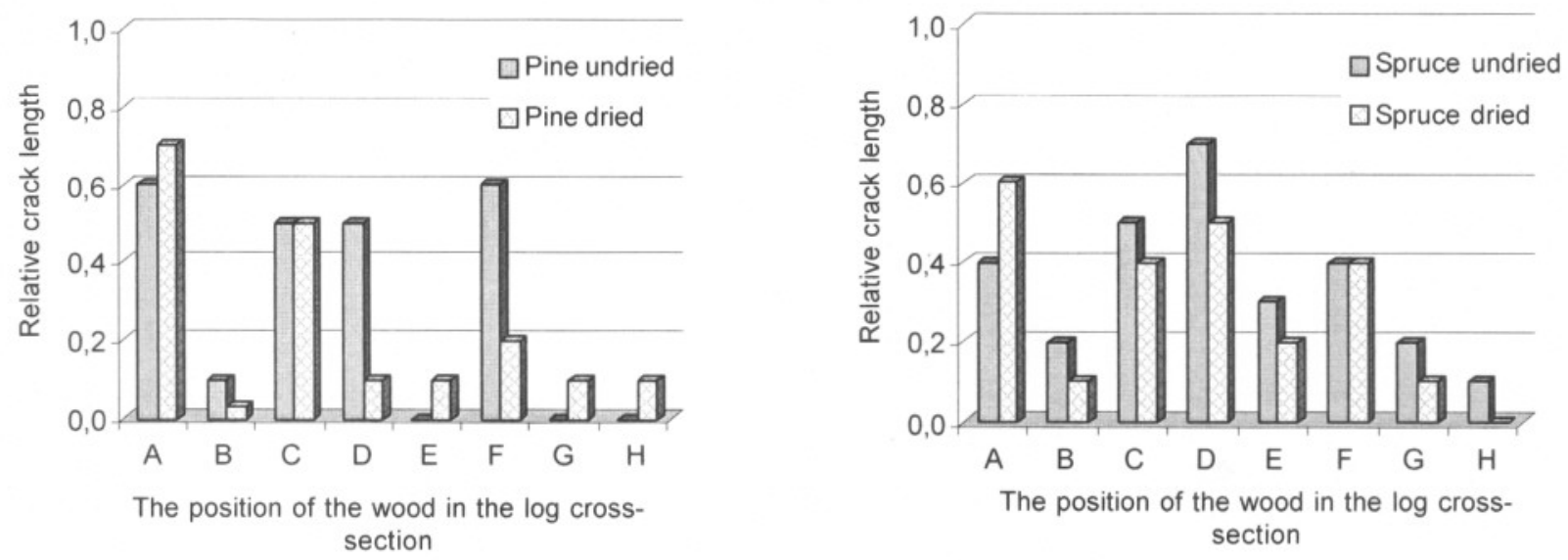

Figure 8a-b. The relative crack length in each annual ring position (A-H), before and after drying for all the samples of pine and spruce 


\section{$3.4 \quad$ Proportion of juvenile wood}

Figure 10 shows the proportion of juvenile wood in groups A-H. The proportion of juvenile wood is more or less the same in pine and spruce. The proportion of juvenile wood in groups $\mathrm{A}, \mathrm{C}$ and $\mathrm{F}$ is ca $30 \%$, which is higher than in the other groups. It was also found that groups D and E have more or less the same proportion of juvenile wood and that, compared with groups A, C and F, group D had a relatively small proportion of juvenile wood. The proportion of juvenile wood in groups $\mathrm{B}, \mathrm{G}$ and $\mathrm{H}$ was less than $5 \%$. In group E, the proportion of juvenile wood was ca. $10 \%$, which is high compared with groups B, G and H, which have also been sawn "far from the pith". The low and high proportions of juvenile wood, respectively, in groups D and E suggest that the difference between these two groups, with respect to the distance from the pith, was not as distinct as was intended when the test was planned.

A relationship has been sought between the proportion of juvenile wood and the extent of the deformations and crack length in the wood. but it has not been possible to find any simple relationship.

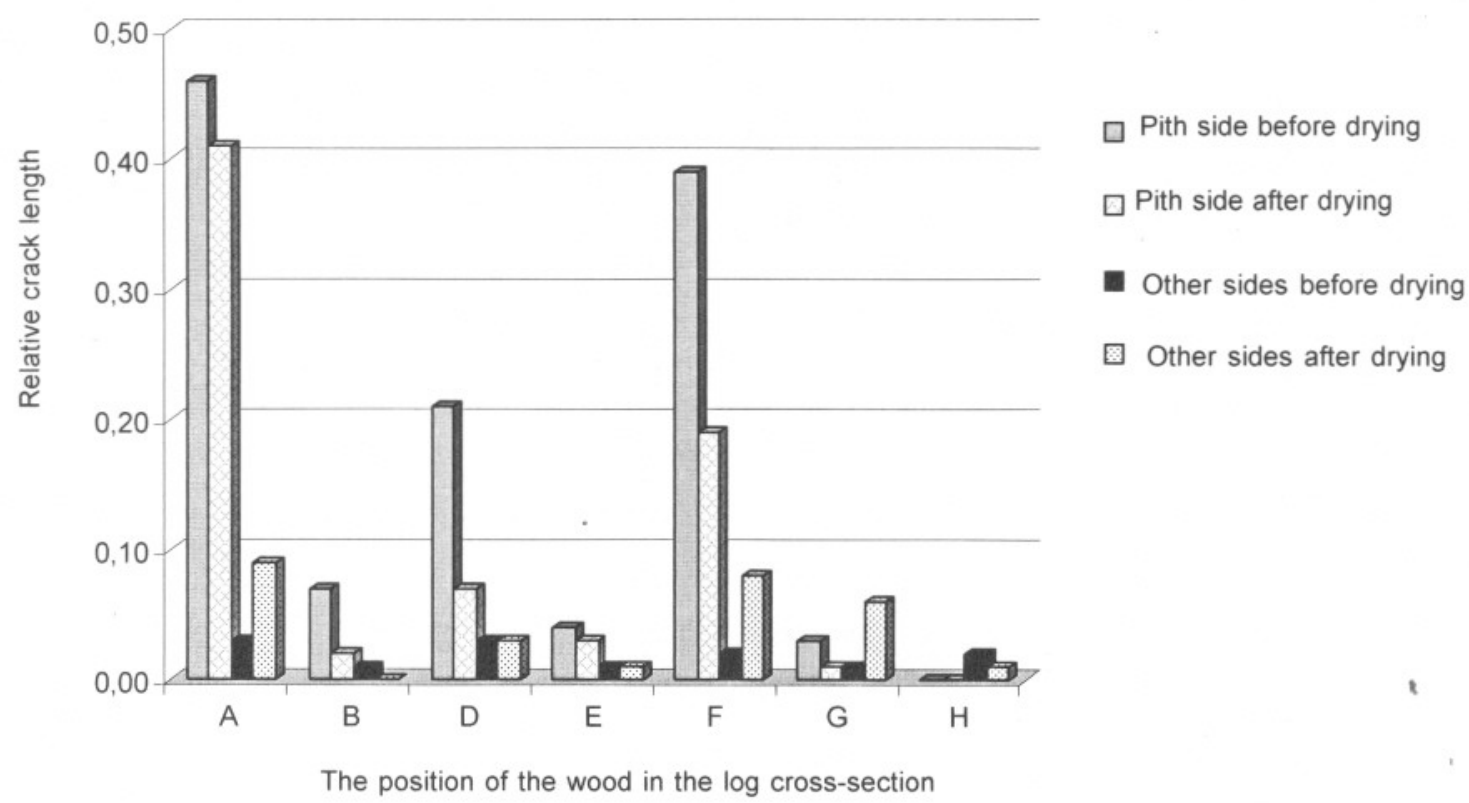

Figure 9. Relative crack length before and after the drying for pith sides, sapwood sides and other sides for pine and spruce in the test groups A-H, except group C.

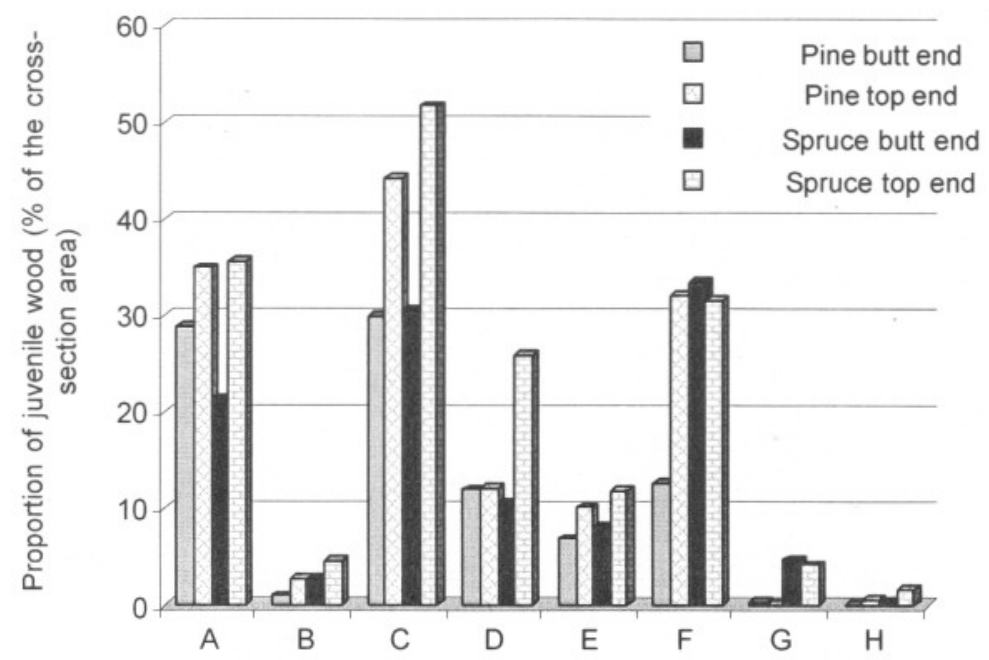

The position of the wood in the log cross-sectio log cross-section

Figure 10. Proportion of juvenile wood in the investigated wood according to definition in chapter 3.4. 


\section{Discussion}

Distotions in the form of bow and crook arise immediately when a log is sawn into boards, figure 5a-d. This is not, however, true of twist and cup, figure 5e-h. This shows that stresses which exist in the living tree, so-called growth stresses, are released by the sawing operation and result in deformation. Growth stresses in pine and spruce consist of longitudinal tensile stresses in the periphery of the log and longitudinal compressive stresses in the central parts of the log (Archer 1987). In the cross-section, the log is tension-loaded and compression-loaded in the radial and tangential directions respectively (Archer 1987). These stresses are also superimposed by more or less local stress fields caused by e.g. reaction wood (Timell 1986).

Depending on how the wood is sawn in relation to the growth stresses, bow and crook develop in the wood, but they vary in both size and direction. This is shown clearly by the results in figures 6a and 7a. In the wood sawn so that one of its faces is more or less tangentially oriented in relation to the annual rings, here is a clear directional dependence of the bow before drying, groups D-H in figure 6a. This wood has an over-representation of pieces with a bow towards the periphery of the log. There is no corresponding directional dependence in the radially sawn wood, groups A-C in figure 6a. This is natural considering the orientation of these pieces in the log cross-section and the growth stresses.

With regard to the wood in groups A and B in figure 7a, it can be seen clearly how the longitudinal compressive and tensile stresses lead to crook. In group A, there is a clear over-representation $(70 \%)$ of pieces which are crooked (concave) towards the sapwood side. In group B, the proportion with crook in the same direction is only $25 \%$. This shows that for wood sawn according to A, the compressive stresses in the central parts of the log interact with the tensile stresses in the periphery of the log so that the wood becomes crooked towards the sapwood side. When the wood closest to the pith is removed, as in group B, this interaction between compressive and tensile stress does not become as manifest and a smaller proportion of the wood in group B becomes crooked towards the sapwood side.

The wood in groups C, F and G has a clear over-representation of crook in one direction, figure 7 a-b. Since these pieces are more or less symmetrical in relation to the pith, it is probable that this directional dependence is a consequence of the marking of the wood during the investigation. There is no directional dependence of bow and crook after drying for wood in these groups.

Bow and crook in dried wood are a result of stresses which exist in the growing tree and which are released in the sawing process, and of the forces which arise as a consequence of shrinkage in the wood material. These forces can either interact with or counteract each other and in combination with the stiffness properties of the wood, they decide the shape of the wood after the drying. In addition, there are, of course, influences of parameters in the drying process on deformations and crack formation in the wood, but these have not however been considered in this study.

Compared with the peripheral wood, juvenile wood exhibits a greater shrinkage along the fibres and less across the fibres, as a consequence of an increase in the microfibril angle and fibre inclination (Zobel et al. 1998). The greater longitudinal shrinkage of the juvenile wood means that the bow caused by growth stresses is counteracted in the drying. This is true primarily for wood pieces in groups $\mathrm{D}$ and F (figure 6a-b), which have juvenile wood along one face. However, it should be noted that the placing in packages and the loading of the wood during the drying means that the wood develops less bow than if the wood had been allowed to dry without restraint in the same climate. This is true of all groups in figure $6 \mathrm{~b}$, and this makes the effect of the shrinkage of the juvenile wood on bow less clear.

The effect of the juvenile wood becomes clearer if we consider the phenomenon of crook, particularly in groups A, B, D and E, figure 7a-b. The wood in groups A and D which has a high proportion of juvenile wood on one edge side of the wood has fewer pieces which develop crook towards the sapwood side during drying. In the case of the wood in groups B and E, where most of the juvenile wood has been sawn away, this change during drying is not as marked. 
Twist is practically non-existent immediately after the sawing process and it does not develop until the wood is dried. This known fact that the twist is primarily caused by an anisotropic shrinkage (see e.g. Balodis 1972) means that the fibre orientation in the wood has an essential importance for the twist. If the fibre direction is not parallel to the longitudinal direction of the wood, the shrinkage during drying will lead to a twisting of the wood.

The twist measured before drying in groups A-G is a result of incorrect measurement or incorrect sawing of the wood, figure 5e-f. Approximately half the triangles in group $\mathrm{H}$ show a twist before drying. After the tests had been completed, it was shown that the sawing method (Sandberg 1996b) used for the production of triangles led to and incorrect sawing of the wood which could be mistaken for twist. It has been established that incorrect sawing is one of the main reasons for the large degree of twist of the wood in group $\mathrm{H}$.

Figure 5g-h shows that the wood with vertical annual rings and where the wood closest to the pith has been removed (group B) does not show any cupping after drying. When the wood closest to the pith is allowed to remain (group A) there is a somewhat smaller thickness shrinkage in this wood compared with the wood further from the pith, and this can be interpreted as cupping. Strictly, it is in this case a question of a shape deviation in the cross-section because of non-uniform shrinkage.

Groups $\mathrm{F}$ and $\mathrm{G}$ show the greatest degree of cupping. The cupping decreases with increasing distance from the pith $(\mathrm{G})$. The triangular wood $(\mathrm{H})$ exhibits relatively little cupping on the tangential surface since this wood was taken close to the periphery of the log.

This shows the well-known fact that cupping of timber has two causes:

a) differences in shrinkage and swelling in the tangential and radial directions, i.e. a shrinkage and swelling anisotropy, and

b) the curvature of the annual rings in the cross section of the timber, when the radius of curvature is small.

If both these conditions are met at the same time, timber which is not loaded to counteract the cupping will become cupped whenever there is a change in moisture content. The smaller the difference between the radial and tangential moisture movements and the greater the radius of curvature of the annual rings in the cross section of the timber, the smaller is the cupping. The cupping will of course also depend on the magnitude of the moisture movements, i.e. there is a dependence on both moisture content and density, and also on the width of the timber.

From these arguments, it follows that undried timber will not exhibit cupping, as also has been shown in the results of this study, figure $5 g-h$.

In this investigation, no consideration has been given to the number, shape and location of the knots in the wood and how these influence the distortion. However, it is generally known that fibre disturbances around the knots can in certain cases cause relatively large distortions in the wood. This is true of large edge knots, which can result in crook, and in particular for so-called splay knots on the faces of radially sawn wood (A, B and H). Such knots often give a strong "kink" of the wood around the knot, and this leads to a bow-like deformation, figure 11 .

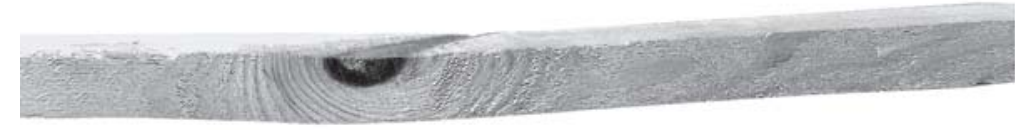

Figure 11. Bow in radially sawn wood caused by a large splay knot on the face of the wood. The picture shows the wood from one of its edge sides. 
It is evident that the mean relative visible crack length before drying is higher in the wood sawn close to the pith (groups A, C, D and F in Figure 8). A closer analysis reveals that the cracks develop to a great extent adjacent to the pith, figure 9 . These cracks are so-called "pith shakes" which radiate out from the pith and become narrower towards the periphery of the trunk (Sandberg 1997a). When the wood is dried, these pith shakes create sites for further cracking, which is consequently greatest in wood sawn close to the pith (Figure 8).

In pine, the crack length increases during drying in the wood, which has been sawn far from the pith (E, $\mathrm{G}$ and $\mathrm{H}$ ) with the exception of wood in group $\mathrm{B}$, where the average crack length is reduced. In wood sawn close to the pith (groups $\mathrm{C}, \mathrm{D}$ and $\mathrm{F}$ ), the crack length decreases or is unchanged during drying. An exception is the annual ring orientation $\mathrm{A}$, which shows a slightly increased crack length.

The change in crack length is significant, but it is a moot point whether a crack which closes in the drying is to be regarded as being shorter than the crack was before drying. From a material technical point of view, the damage still remains in the wood although the crack is not visible to the naked eye. That the chemical bonds should have been recreated in the crack area during the drying is out of the question.

The tendency for the region closest to the pith to visible crack becomes even clearer if the visible crack length is considered for the wood surfaces separately. The wood surfaces which are sawn in connection to the pith, i.e. pith sides for $\mathrm{A}, \mathrm{D}$ and $\mathrm{F}$ in figure 9 , have the absolutely highest value for relative crack length. The difference between groups $A$ and $B$ and groups $F$ and $G$, with respect to the occurrence of cracks on the pith sides is very clear. In wood with the annual ring orientations A and F, the cracks widen on the pith sides during drying towards the adjacent sides. This is the explanation for the relatively large increase in visible crack length on the "other sides" which takes place in groups A and $\mathrm{F}$ during drying, as shown in figure 9.

\section{Conclusions}

These results show unambiguously that the orientation of the annual rings in the cross section of the wood and the position of the wood in relation to the pith are important factors affecting the distortion and cracking of the wood. It should however be noted that the wood used for the investigation was primarily intended for star-sawing, i.e. consisted of large butt logs and middle logs, and this means that it is inadvisable to draw general con-clusions from the results. Never-theless it can be said that, if largesized logs are to be sawn, then star-sawing or some similar method of sawing is a suitable technique if straight and crack-free wood is desired. 


\section{References}

Archer RR(1987) Growth stresses and strains in trees. Springer, Berlin, Heidelberg, New York

Balodis V (1972) Influence of grain angle on twist in seasoned boards. Wood Science, 5(1)

CEN (1995) European Standard EN 844-3 (3.21) Round and sawn timber - Terminology. Part 3: General terms for sawn timber. Comité Européen de Normalisation

Danborg F (1990) The effect of silvicultural practise on the amount and quality of juvenile wood in Norway spruce. Paper presented at the IUFRO-World Congress, Montreal Canada

Hallock H (1965) Sawing to reduce warp of loblolly pine studs. USDA Forest Service, For. Prod. Lab. Research paper FPL-51, Madison USA

Montgomery DC (1991) Design and analysis of experiments. Third edition, John Wiley \& Sons, Inc. New York

Perstorper M, Pellicane PJ, Klieger IR, Johansson G (1995) Quality of timber products from Norway spruce. Part 2. Influence of spatial position and growth characteristics on warp. Wood Sci Technol 29:339-352

Sandberg D (1995) Vertical annual rings in pine (Pinus silvestris L) and spruce (Picea abies Karst). KTH-Royal Institute of Technology, Dept. of Manufacturing Systems, Wood Technology and Processing, Report TRITA-TRÄ R-95-13

Sandberg D (1996a) The influence of pith and juvenile wood on proportion of cracks in sawn timber when kiln dried and exposed to wetting cycles. Holz als Roh- und Werkstoff 54(3)

Sandberg D (1996b) Radially sawn timber. Star-sawing - a new method for producing timber with vertical annual rings. Holz als Roh- und Werkstoff 54(3)

Sandberg D (1997a) Radially sawn timber. The influence of annual ring orientation on crack formation and deformation in water soaked pine (Pinus silvestris L) and spruce (Picea abies Karst) timber. Holz als Roh- und Werkstoff 55(3)

Sandberg D (1997b) Weathering of radial and tangential wood surfaces of pine and spruce. Holzforschung / Vol. 53 / 1999 / No. 4.

Sandberg D (1998) Value activation with vertical annual rings - material, production, products. KTHRoyal Institute of Technology, Dept. of Manufacturing Systems, Wood Technology and Processing, Report TRITA-TRÄ R-98-36

Söderström O (1990) Drying checks and end moisture contents. Trätek- Swedish Institute for Wood Technology Research, Report I 9011062

Timell TE (1986) Compression Wood in Gymnosperms. Springer, Berlin, Heidelberg, New York

Zobel BJ, Sprauge JR (1998) Juvenile wood in forest trees. Springer, Berlin, Heidelberg, New York 